\title{
Bat aggregational response to pest caterpillar emergence
}

\begin{abstract}
Ján Blažek ${ }^{\bowtie}$, Adam Konečný \& Tomáš Bartonička
Moths (Lepidoptera) are major agricultural and forest pests in many parts of the world, including Europe, with many causing great economic damage to crops, horticultural plants, stored items, and wool products. Here, we focus on two ecologically similar inchworms, Operophtera brumata and Erannis defoliaria, known for their high foliage consumption during the spring emergence of caterpillars. We hypothesise that bats could play a role in reducing pests such as caterpillars by switching to this abundant emerging prey. At two infested and one control forest sites, caterpillars were sampled during spring to determine levels of infestation. At the same time, bat flight activity was monitored during the peak in caterpillar abundance. During the spring caterpillar outbreak, we collected faecal samples of forest-dwelling bats capable of using gleaning. The majority of samples were positive for our focus species, being $\mathbf{5 1 . 8 5 \%}$ for 0 . brumata and $29.63 \%$ for $E$. defoliaria faecal samples. The foraging activity of two gleaning bats, Myotis nattereri and Myotis bechsteinii, increased at both infested sites, but not at the control site, during caterpillar emergence, as did foraging of Plecotus auritus/austriacus, which used both gleaning and aerial hawking. We conclude that both specialists and occasional gleaners, which prefer different prey but are able to switch their foraging strategies, aggregate at sites during pest emergence and, as such, our results confirm the high potential of bats to reduce numbers of pest species such as caterpillars.
\end{abstract}

A predator's effect on prey populations is generally studied using numerical responses ${ }^{1,2}$ driven by two mechanisms, migration of predators to sites with high prey concentrations (aggregational response) and predator reproduction, which results in a delayed increase in the density of predators ${ }^{3}$. While a numerical response is usually expected for predators that specialise on certain prey, an aggregational response can be observed even in opportunistic generalist predators such as insectivorous bats. Bats, therefore, have the potential to act as an important pest control species, even if they only forage on such species occasionally, e.g., during outbreaks. Indeed, ecosystem services provided by bats are now considered of high economic importance ${ }^{4,5}$.

Given the high diversity of bat species and their varying foraging strategies, they have the potential to consume a wide range of arthropod pests within crop fields or agroforests ${ }^{6,7}$. A number of recent studies have identified arthropod species consumed by insectivorous bats and defined their role as regular predators ${ }^{8-11}$, especially following the rapid development of DNA metabarcoding methods that allow for the processing of multiple samples to identify different bat prey taxa ${ }^{12,13}$. However, the consumption of a pest does not indicate a predator's ability to control its numbers ${ }^{7}$.

To declare a bat species capable of biocontrol on a certain pest, one needs to identify (1) that the bat forages on a pest regularly, (2) that it aggregates at a site where the pest accumulates, possibly shifting to a more effective foraging strategy, and (3) that the bat consumes enough of the pest to prevent massive outbreaks. To date, biocontrol has only been confirmed for Tadarida brasiliensis in the USA ${ }^{14,15}$, and there have been no comprehensive studies on the ability of bats to exert biocontrol in Europe. Although some studies have shown that bats can forage on pests at the stage of the outbreak ${ }^{5,16,17}$, there is still a lack of studies showing that bats actively aggregate at sites of mass pest occurrence to forage intensively upon it.

Every year, European deciduous forests are threatened by population overgrowth of pest defoliators, particularly moths ${ }^{18,19}$. While bats are significant predators of moths ${ }^{20}$, consumption of adult moths does not lead to an automatic reduction in caterpillars ${ }^{7}$, which are the main cause of foliage damage ${ }^{14}$. Theoretically, bats are potentially important predators of pest caterpillars as they have a suitable foraging strategy and occupy the same habitat as the pest during its emergence. Aside from three studies, regular consumption of caterpillars by Central European bats has not been well documented. Andreas et al. ${ }^{21}$, for example, detected caterpillars in the diet of three forest-dwelling bat species (Plecotus auritus, Myotis bechsteinii, and Myotis nattereri) using morphological analysis of faeces, while Vesterinen et al. ${ }^{22}$ detected pest caterpillars of the geometrid Agriopis aurantiaria in the diet of Myotis brandtii. Hope et al. ${ }^{23}$ molecularly confirmed and morphologically identified the consumption 


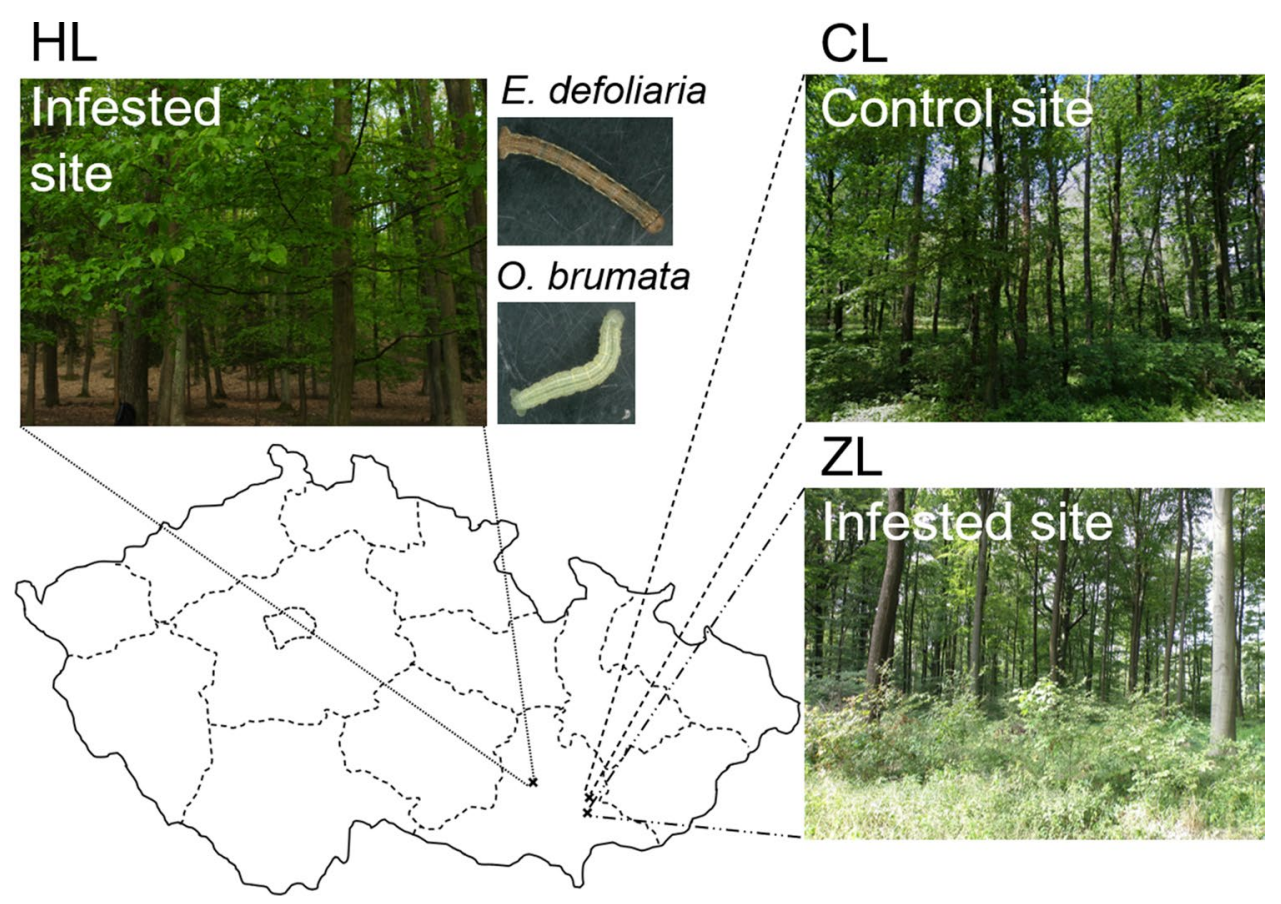

Figure 1. Sampling sites. $\mathrm{ZL}=\check{Z}$ dánický forest, $\mathrm{HL}=$ Holedná game reserve (both sites with regular massive caterpillar outbreaks), $\mathrm{CL}=$ control site. Map was generated in MS PowerPoint v2104 (www.microsoft.com).

\begin{tabular}{|l|l|l|l|l|l|}
\hline Site & Caterpillars & E. defoliaria & O. brumata & Other caterpillars & Other Arthropoda \\
\hline \multirow{2}{*}{ CL } & Sampled & 3 & 18 & 16 & 3 \\
\cline { 2 - 6 } & Average per branch & 0.2 & 1.2 & 1.07 & 0.2 \\
\hline \multirow{2}{*}{ ZL } & Sampled & 37 & 61 & 31 & 15 \\
\cline { 2 - 6 } & Average per branch & 2.47 & 4.07 & 2.07 & 1 \\
\hline \multirow{2}{*}{ HL } & Sampled & 39 & 61 & 66 & 3 \\
\cline { 2 - 6 } & Average per branch & 2.6 & 4.07 & 4.4 & 0.2 \\
\hline
\end{tabular}

Table 1. Arthropod prey availability at the three study sites. $C L$ control site, $Z L$ Ždánický forest, $H L$ Holedná game reserve.

of caterpillars by gleaning bat M. nattereri. Finally, while there have been several recent studies focused on the ecosystem services provided by bats ${ }^{10,24-26}$, none have focused on the consumption of caterpillars causing significant damage to forests.

To assess the biocontrol potential of gleaning bats regarding forest pest inchworms, we employed a holistic approach that involved (1) monitoring bat acoustic activity during pest emergence to confirm aggregation at overpopulation sites; (2) detecting pest caterpillars in bat droppings using morphological and molecular analysis; and (3) evaluation of caterpillar density and foliage damage in infested and control forest sites to estimate pest impact.

\section{Results}

Caterpillar availability. The study was conducted on three sites (Fig. 1). Sites ZL and HL were marked by foresters as regularly infested by pest caterpillars. Site CL was picked as the control site because no such outbreaks occurred there. Two caterpillar species, Erannis defoliaria and Operophtera brumata, dominated at each site (ZL $68.06 \%$, HL 59.17\%, CL 52.5\%), with O. brumata always more abundant than E. defoliaria. At ZL and HL, there were almost three times more O. brumata and ten times more E. defoliaria than at CL (Table 1). Despite a similar pest caterpillar proportion at all sites, the number of pest caterpillars per branch was significantly lower at CL than ZL or HL (median: 1, 7 and 5, respectively; $\mathrm{H}_{(2,45)}=20.91, p<0.001$; Fig. 2). In comparison to lepidopteran caterpillars, other arthropods were the minority at all study sites (Table 1).

Foliage loss during pest emergence. GLMs indicated that foliage loss was significantly influenced by both total number of No. Caterpillars (Wald $\chi^{2}(1)=9.05, p<0.01$ ) and SITE (Wald $\chi^{2}(2)=18.04, p<0.001$ ). Foliage loss was lowest at CL (Median: 4.9\%; MAX: 14.6\%; MIN: 0.4\%; Fig. 3), which corresponded with the relatively low number of caterpillars detected (Table 1). Overpopulation sites with a higher number of caterpillars per 


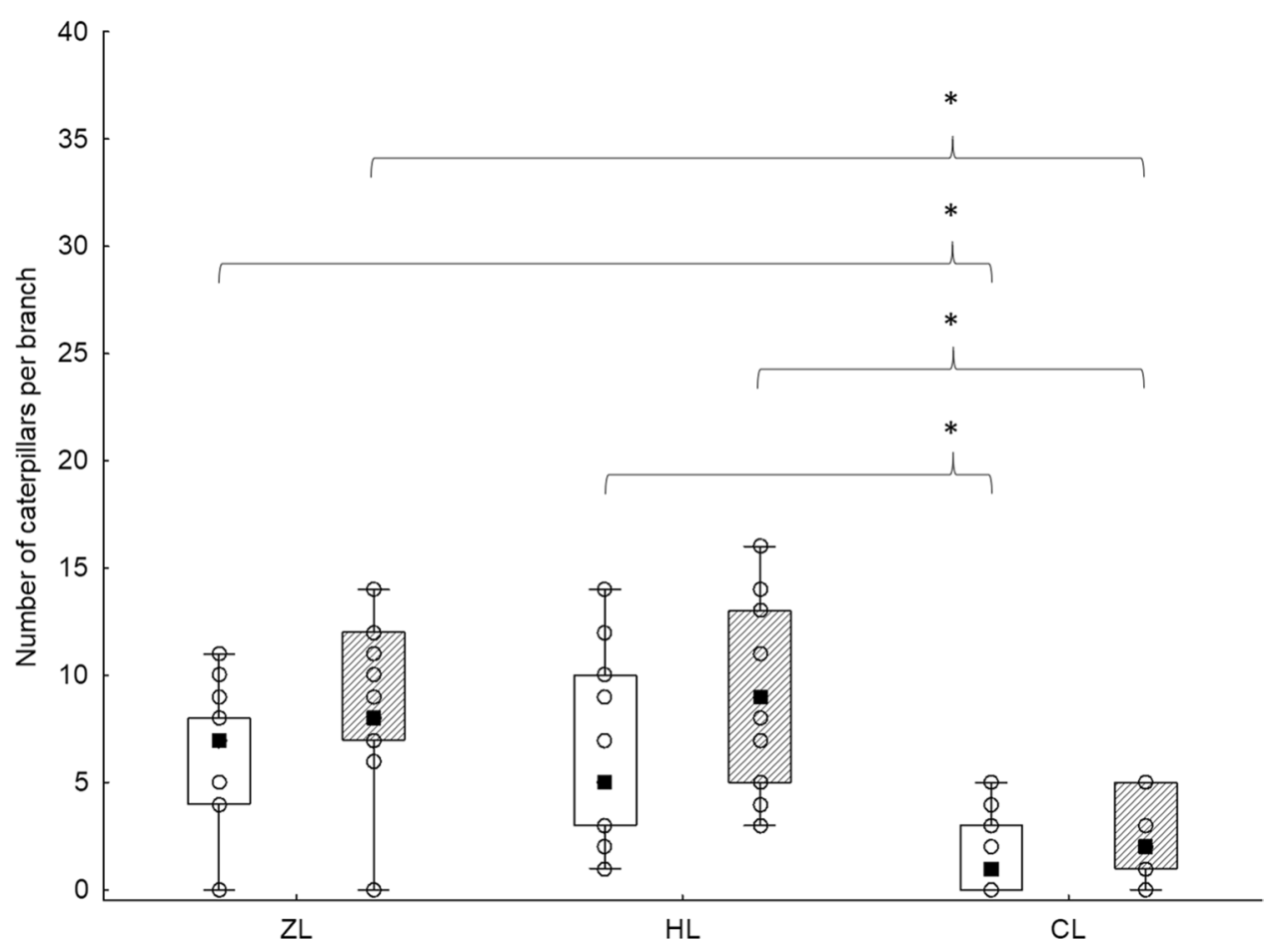

Figure 2. Number of caterpillars per branch $(\mathrm{n}=15)$. Clear box $=$ E. defoliaria and O. brumata caterpillars, Dashed box $=$ all caterpillars; $\mathbf{\square}=$ median; box $=\mathrm{Q} 1-\mathrm{Q} 3$; whiskers $=$ range; $\mathrm{O}=$ source data . Data were compared using the Kruskal-Wallis $\mathrm{H}$ test $\left({ }^{(*)} p \leq 0.001\right)$.

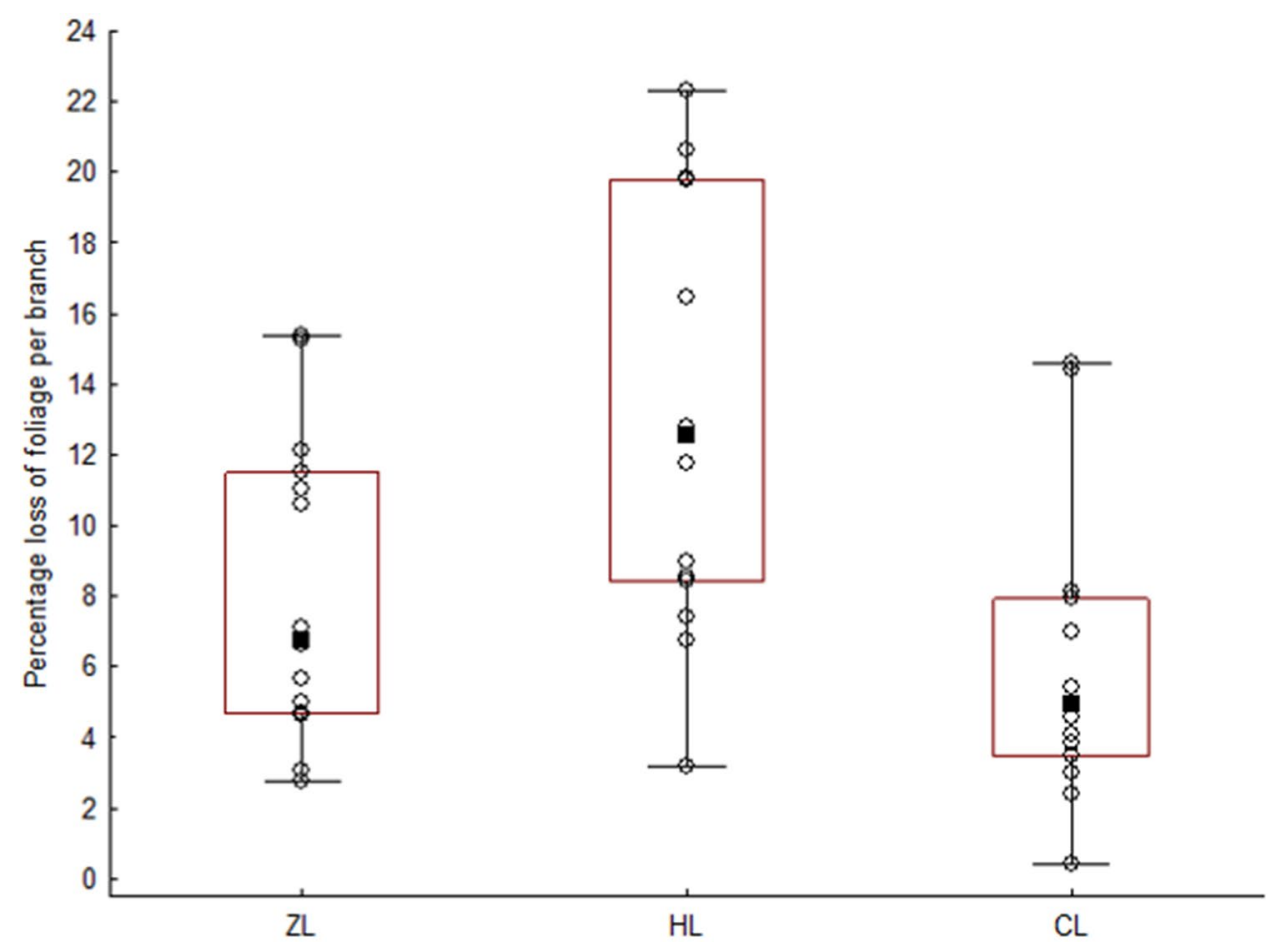

Figure 3. Foliage loss per branch at Ždánický forest (ZL), the Holedná game reserve (HL), and the control site $(\mathrm{CL}), \mathrm{n}=15$ at each site. $\mathbf{\square}=$ median; box $=\mathrm{Q} 1-\mathrm{Q} 3$; whiskers = range; $\mathrm{O}=$ source data. 


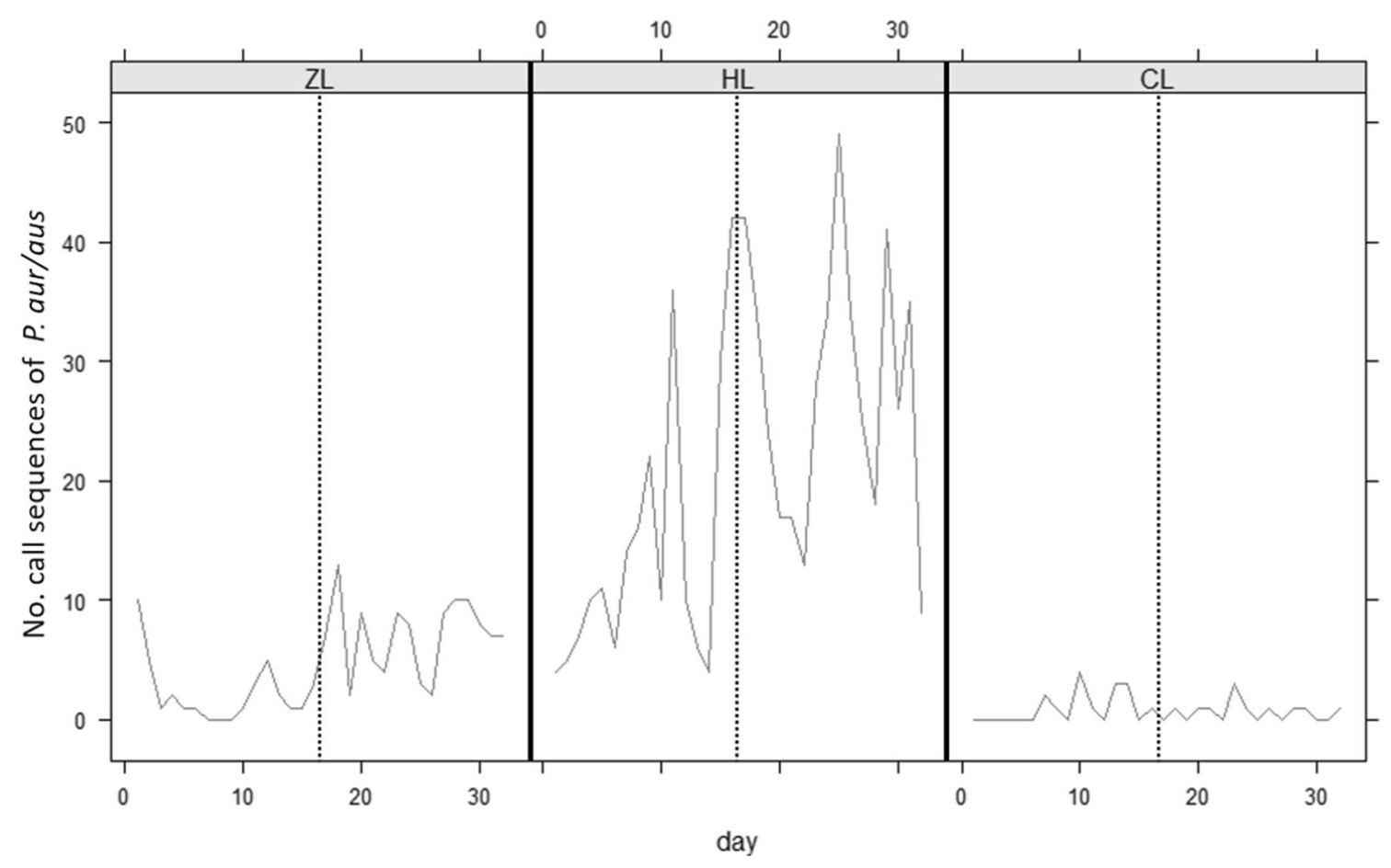

Figure 4. Flying activity of $P$. auritus/austriacus at the sample sites, presented as recorded call sequences per day. The dotted line divides the time periods "before" and "during" peak abundance.

branch displayed significantly higher foliage loss (ZL= Median: 6.8\%; MAX: 15.4\%; MIN: 2.8\%; HL= Median: 12.5\%; MAX: 22.3\%; MIN: 3.2\%; Fig. 3).

Bat flying activity. Analysis of bat activity was focused on Plecotus auritus and Plecotus austriacus (grouped together as Plecotus; opportunistic gleaners), and Myotis bechsteinii and Myotis nattereri (grouped together as Myotis; solely gleaners) due to their known use of gleaning. Bat activity differed significantly between sites for both bat groups (Plecotus: Wald $\chi^{2}(2)=2.62^{\star} 10^{11}, p<0.001 ;$ Myotis: $\chi^{2}(2)=4.21^{\star} 10^{11}, p<0.001$ ), with higher flying activity recorded at HL and ZL than CL (Figs. 4, 5). There was also a significant increase in flying activity for both bat groups in relation to caterpillar abundance before and during the abundance peak at $\mathrm{HL}$ and ZL (Plecotus: $\chi^{2}(1)=58, p<0.001$; Myotis: $\chi^{2}(1)=11, p<0.001$ ), with no increase observed at CL (Figs. 4,5 ).

Dietary analysis. Morphological analysis confirmed the remains of caterpillars in more than half of all faecal samples (51.85\%; Table 2), with most being found in the droppings of $M$. nattereri (57.14\% occurrence). As morphological analysis does not allow identification of species, we focused more on molecular confirmation for this purpose. Metabarcoding analysis confirmed 189 arthropod species of which 129 species were Lepidoptera. From the 129 Lepidoptera identified, we found 23 pest caterpillar species (termed "certain caterpillar") and 26 pest species that had juvenile and adult stages that overlapped during the sampling period, meaning we could not say whether they were eaten as adult moths or caterpillars (termed "possible caterpillar"). All 81 samples were positive for at least one certain pest caterpillar, and the majority (74.07\%) were positive for at least five certain pest caterpillar species.

The most frequent certain caterpillar found was that of Dichonia convergens, with caterpillars of our focal species O. brumata the second most frequent (51.85\%; Table 2). Occurrence of O. brumata was similar across bat species, with $54.55 \%$ of Plecotus spp., $57.14 \%$ of $M$. nattereri, and $48.78 \%$ of $M$. bechsteinii faecal samples. In comparison, the frequency of occurrence of the second focus species, E. defoliaria, was just $29.63 \%$ in all samples. In bat species, E. defoliaria was detected in $29.27 \%$ of $M$. bechsteinii, $33.33 \%$ of Plecotus spp., and only $14.29 \%$ of $M$. nattereri faecal samples, its lower representation probably reflecting its lower availability in the environment. Other important pests of deciduous trees detected included Agriopis aurantiaria at $45.68 \%$ and Agriopis leucophaearia at $9.88 \%$ (Table 2).

Four species that may have been hunted by bats as both moth and caterpillar stages (Panolis flammea, Conistra erythrocephala, Drymonia ruficornis, Polyploca ridens) were molecularly confirmed more frequently than all other prey species that were definitely at the caterpillar stage at the time of the study (76-99\%oc; Table 2).

\section{Discussion}

Our results confirmed that Myotis species, such as Myotis nattereri and Myotis bechsteinii, aggregate at sites of mass caterpillar occurrence and systematically forage upon them. As far as we know, this is the first observation of an aggregational response by bats against caterpillars. On the other hand, the aggregation of a predator that specialises on gleaning is not so surprising if we are focusing on caterpillars. What may be more important in this 


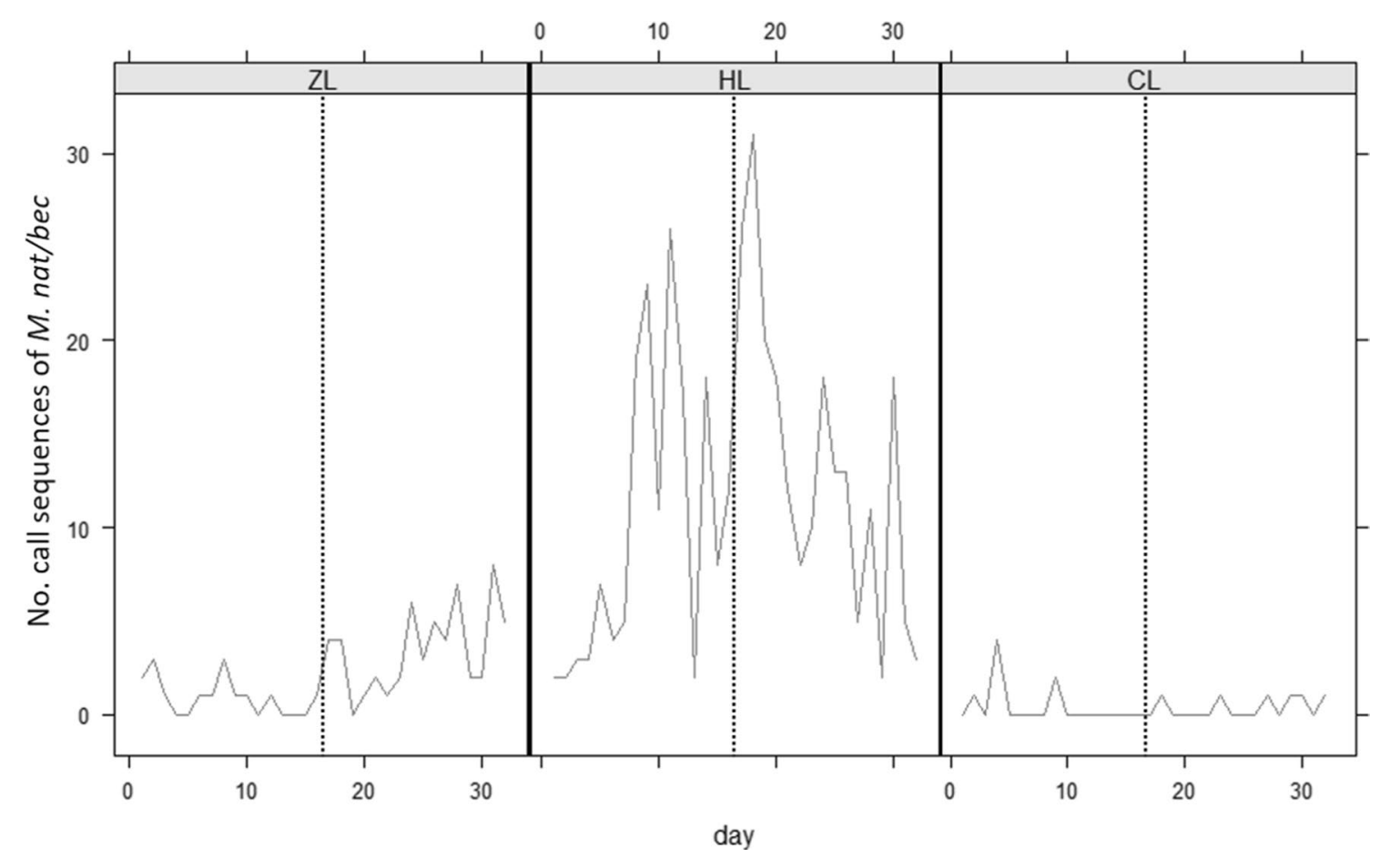

Figure 5. Flying activity of $M$. nattereri/bechsteinii at the sample sites, presented as recorded call sequences per day. The dotted line divides the time periods "before" and "during" peak abundance.

case, therefore, is the confirmation of mass aggregation by a predator that displays multiple foraging strategies and can switch strategies during the year ${ }^{27}$, i.e., Plecotus spp. Since the different arthropod groups differ in availability during the year, we hypothesised that generalist facultative predators, such as bats, could play an important role in reducing pest invasion (biocontrol), with the importance of different species increasing with their ability to utilise food types in proportion to their availability ${ }^{15}$, as was indeed observed in this study.

Flying activity of these gleaning bats increased significantly with peak caterpillar abundance, while activity remained unchanged at the control site throughout the observation period. Until now, relatively few studies have reported the emergence of adult pest insects as an aggregational response trigger in bats $\mathrm{s}^{26,28,29}$. Spatio-temporal matching between emergent moths and foraging bats, with bat activity increasing significantly with moth abundance, has previously been observed by Charbonnier at el. ${ }^{30}$, and an aggregational three-dimensional response was also confirmed by Krauel et al. ${ }^{31}$, who observed higher bat activity at higher altitudes when the abundance of migratory moths was high.

We observed slight differences in the diet of the two focus Myotis species in this study, with dietary patterns similar to those found by Gregor \& Bauerova ${ }^{32}$, Swift ${ }^{33}$, and Taake ${ }^{34}$ for M. nattereri, and Andreas et al. ${ }^{21}$ and Vaughan $^{35}$ for $M$. bechsteinii. Both showed similar foraging strategies, concentrating on stable prey resources in highly cluttered habitats by gleaning on leaf surfaces, using prey-generated sound alone for detection ${ }^{36}$, though both can employ aerial hawking in exceptional cases ${ }^{37}$. In comparison, Plecotus auritus is better able to utilise the nonregular distribution of ephemeral food resources thanks to its more common use of aerial hawking ${ }^{38,39}$. While only $10-40 \%$ of $P$. auritus diet is composed of terrestrial arthropods caught by gleaning ${ }^{33,40}$, it is generally accepted that the species uses aerial hawking in more than $50 \%$ of prey capture attempts ${ }^{41}$, making $P$. auritus a more generalist feeder than both Myotis species.

Caterpillars represent an excellent food source for gleaning bats, particularly during their peak abundance in spring; nevertheless, confirmation of their consumption by bats is almost absent in the literature. Our data show that over half of the bats sampled had morphologically identified caterpillar remains in their faeces. This is relatively high compared to the study of Andreas et al. ${ }^{21}$, who found $25.9 \%$ oc in M. bechsteinii, $18.8 \%$ oc in $M$. nattereri, and $12.1 \%$ oc in $P$. auritus faecal samples. However, Andreas et al. ${ }^{21}$ sampled from March to November to increase the amount of dietary data obtained, and these bats focus on caterpillar feeding during their summer emergence, which is consistent with opportunistic foraging on caterpillars. Furthermore, $100 \%$ of our samples were molecularly confirmed as containing remains of pest caterpillars, with Operophtera brumata confirmed at around $50 \%$ oc in all bat species studied, only Dichonia convergens occurring more frequently at $60-85 \%$ oc. PuigMontserrat et al. ${ }^{26}$ noted that Pipistrellus pygmaeus predation had a significant impact on the rice borer moth Chilo supressalis, despite it only occurring in 50\%oc of faecal samples. This would indicate that insectivorous bats preying on a vast array of arthropod species, are able to reduce pest species when their percentage occurrence in the diet is around $50 \%$.

While O. brumata and Erannis defoliaria caterpillars were the most frequently occurring gleanable prey at our sites, they were not the most frequently taken pest taxa in the faecal samples, the most foraged taxa belonging to pest moths with overlapping stages. Overall, four "possible caterpillar" species were taken more often than 


\begin{tabular}{|c|c|c|c|c|c|}
\hline \multirow{2}{*}{\multicolumn{2}{|c|}{ Morphological identification of caterpillars }} & \multirow{3}{*}{\begin{tabular}{|l|} 
All samples $(\mathbf{n}=\mathbf{8 1})$ \\
$51.9 \%$ \\
\end{tabular}} & \multirow{3}{*}{\begin{tabular}{|l|} 
P. aur/aus $(\mathbf{n}=\mathbf{3 3})$ \\
$48.5 \%$ \\
\end{tabular}} & \multirow{3}{*}{\begin{tabular}{|l|} 
M. nat $(\mathbf{n}=7)$ \\
$57.1 \%$ \\
\end{tabular}} & \multirow{3}{*}{\begin{tabular}{|l|} 
M. $\operatorname{bec}(\mathbf{n}=41)$ \\
$53.7 \%$
\end{tabular}} \\
\hline & & & & & \\
\hline Caterpillar & Molecular confirmation & & & & \\
\hline $\mathrm{p}$ & Panolis flammea & $98.8 \%$ & $97 \%$ & $100 \%$ & $100 \%$ \\
\hline $\mathrm{p}$ & Conistra erythrocephala & $96.3 \%$ & $93.9 \%$ & $100 \%$ & $97.6 \%$ \\
\hline $\mathrm{p}$ & Drymonia ruficornis & $93.8 \%$ & $97 \%$ & $85.7 \%$ & $92.7 \%$ \\
\hline $\mathrm{p}$ & Polyploca ridens & $76.5 \%$ & $84.9 \%$ & $100 \%$ & $65.9 \%$ \\
\hline c & Dichonia convergens & $72.8 \%$ & $60.6 \%$ & $85.7 \%$ & $80.5 \%$ \\
\hline $\mathrm{p}$ & Selenia tetralunaria & $70.4 \%$ & $57.6 \%$ & $100 \%$ & $75.6 \%$ \\
\hline $\mathrm{p}$ & Conistra rubiginosa & $61.7 \%$ & $51.5 \%$ & $85.7 \%$ & $65.9 \%$ \\
\hline $\mathrm{p}$ & Tortrix viridana & $60.5 \%$ & $51.5 \%$ & $85.7 \%$ & $63.4 \%$ \\
\hline $\mathrm{p}$ & Orthosia cerasi & $59.3 \%$ & $57.6 \%$ & $57.1 \%$ & $61 \%$ \\
\hline $\mathrm{p}$ & Orthosia gothica & $56.8 \%$ & $60.6 \%$ & $57.1 \%$ & $53.7 \%$ \\
\hline $\mathrm{c}$ & Operophtera brumata & $51.9 \%$ & $54.6 \%$ & $57.1 \%$ & $48.8 \%$ \\
\hline $\mathrm{p}$ & Agriopis marginaria & $49.4 \%$ & $45.5 \%$ & $57.1 \%$ & $51.2 \%$ \\
\hline $\mathrm{c}$ & Alsophila aceraria & $48.2 \%$ & $30.3 \%$ & $57.1 \%$ & $61 \%$ \\
\hline c & Minucia lunaris & $48.2 \%$ & $51.5 \%$ & $28.6 \%$ & $48.8 \%$ \\
\hline $\mathrm{p}$ & Hypomecis roboraria & $45.7 \%$ & $36.4 \%$ & $42.9 \%$ & $53.7 \%$ \\
\hline $\mathrm{p}$ & Orthosia incerta & $45.7 \%$ & $42.4 \%$ & $85.7 \%$ & $41.5 \%$ \\
\hline c & Agriopis aurantiaria & $45.7 \%$ & $27.3 \%$ & $85.7 \%$ & $53.7 \%$ \\
\hline $\mathrm{p}$ & Diurnea fagella & $44.4 \%$ & $54.6 \%$ & $57.1 \%$ & $34.2 \%$ \\
\hline c & Ennomos quercinarius & $43.2 \%$ & $27.3 \%$ & $85.7 \%$ & $48.8 \%$ \\
\hline c & Griposia aprilina & $40.7 \%$ & $33.3 \%$ & $14.3 \%$ & $51.2 \%$ \\
\hline $\mathrm{p}$ & Eupithecia abbreviata & $38.3 \%$ & $48.5 \%$ & $28.6 \%$ & $31.7 \%$ \\
\hline c & Catocala sponsa & $38.3 \%$ & $15.2 \%$ & $42.9 \%$ & $56.1 \%$ \\
\hline $\mathrm{p}$ & Lithophane ornitopus & $37 \%$ & $33.3 \%$ & $71.4 \%$ & $34.2 \%$ \\
\hline c & Pandemis cerasana & $32.1 \%$ & $21.2 \%$ & $42.9 \%$ & $39 \%$ \\
\hline $\mathrm{p}$ & Alsophila aescularia & $30.9 \%$ & $30.3 \%$ & $42.9 \%$ & $29.3 \%$ \\
\hline $\mathrm{p}$ & Ectropis crepuscularia & $30.9 \%$ & $21.2 \%$ & $57.1 \%$ & $34.2 \%$ \\
\hline c & Erannis defoliaria & $29.6 \%$ & $33.3 \%$ & $14.3 \%$ & $29.3 \%$ \\
\hline c & Pennithera firmata & $29.6 \%$ & $21.2 \%$ & $42.9 \%$ & $34.2 \%$ \\
\hline $\mathrm{p}$ & Lycia pomonaria & $27.2 \%$ & $18.2 \%$ & $71.4 \%$ & $26.8 \%$ \\
\hline c & Amphipyra berbera & $27.2 \%$ & $33.3 \%$ & $14.3 \%$ & $24.4 \%$ \\
\hline $\mathrm{p}$ & Lycia hirtaria & $25.9 \%$ & $24.2 \%$ & $42.9 \%$ & $24.4 \%$ \\
\hline $\mathrm{p}$ & Phigalia pilosaria & $25.9 \%$ & $21.2 \%$ & $0 \%$ & $34.2 \%$ \\
\hline c & Dioryctria abietella & $22.2 \%$ & $18.2 \%$ & $57.1 \%$ & $19.5 \%$ \\
\hline c & Colotois pennaria & $21 \%$ & $15.1 \%$ & $42.9 \%$ & $22 \%$ \\
\hline c & Dendrolimus pini & $21 \%$ & $12.1 \%$ & $57.1 \%$ & $22 \%$ \\
\hline $\mathrm{p}$ & Cabera pusaria & $19.8 \%$ & $24.2 \%$ & $14.3 \%$ & $17.1 \%$ \\
\hline $\mathrm{c}$ & Cosmia trapezina & $19.8 \%$ & $12.1 \%$ & $28.6 \%$ & $24.4 \%$ \\
\hline $\mathrm{p}$ & Conistra rubiginea & $17.3 \%$ & $12.1 \%$ & $42.9 \%$ & $17.1 \%$ \\
\hline $\mathrm{c}$ & Amphipyra pyramidea & $17.3 \%$ & $3 \%$ & $57.1 \%$ & $22 \%$ \\
\hline c & Dryobotodes eremita & $17.3 \%$ & $12.1 \%$ & $14.3 \%$ & $22 \%$ \\
\hline c & Archips xylosteana & $16.1 \%$ & $9.1 \%$ & $14.3 \%$ & $22 \%$ \\
\hline c & Mesogona acetosellae & $13.6 \%$ & $24.2 \%$ & $0 \%$ & $7.3 \%$ \\
\hline $\mathrm{c}$ & Eudemis profundana & $11.1 \%$ & $9.1 \%$ & $0 \%$ & $14.6 \%$ \\
\hline $\mathrm{p}$ & Agriopis leucophaearia & $9.9 \%$ & $3 \%$ & $0 \%$ & $17.1 \%$ \\
\hline $\mathrm{p}$ & Biston stratarius & $8.6 \%$ & $6.7 \%$ & $0 \%$ & $12.2 \%$ \\
\hline $\mathrm{p}$ & Orthosia cruda & $8.6 \%$ & $3 \%$ & $14.3 \%$ & $12.2 \%$ \\
\hline c & Ancylis mitterbacheriana & $8.6 \%$ & $9.1 \%$ & $0 \%$ & $9.8 \%$ \\
\hline c & Archips oporana & $7.4 \%$ & $6.1 \%$ & $14.3 \%$ & $7.3 \%$ \\
\hline $\mathrm{p}$ & Eupithecia lanceata & $4.9 \%$ & $9.1 \%$ & $0 \%$ & $2.4 \%$ \\
\hline
\end{tabular}

Table 2. Percentage occurrence of morphologically identified caterpillar remains and molecularly confirmed pest caterpillars. As the life stages of several pest species overlapped over the study period, we could not say whether they were consumed as adult moths or as caterpillars; hence, these are marked as "p" (possible caterpillars). Pest species that occur only as caterpillars are marked as "c" (certain caterpillar). Species are sorted from the highest occurrence to the lowest. 
any "certain caterpillar" pest species (Table 2). While consumption of adult stages does not automatically lead to pest reduction ${ }^{7}$, it may be still important for biocontrol if their occurrence in faecal samples is suitably high ${ }^{26}$. More effective suppression would occur in cases of predation by multiple species ${ }^{25}$. This is likely to be the case for O. brumata, which is targeted during both its spring and autumn emergences by multiple bat species ${ }^{23,42}$.

We measured foliage loss at all three sites as a proxy for tree damage and caterpillar activity/abundance. Foliage loss also acts as an indicator of a tree's reaction to environmental stress and may serve as an indicator of continued vitality ${ }^{43}$. As expected, foliage loss was higher at infested sites, with levels of $6.8 \%$ at ZL and $12.5 \%$ at HL compared with $4.9 \%$ at the CL site. While such damage levels may seem insignificant in relation to the defoliation caused by other pests (e.g., the European gypsy moth Lymantria dispar ${ }^{44}$; the nun moth Lymantria monachal ${ }^{45}$ ), the reduction is visible in the first stages of foliage deficit and significantly slows down tree growth, with $1 \%$ foliage loss equivalent to a $\sim 1 \%$ decrease in growth rate ${ }^{43,46}$. Furthermore, geometrid caterpillars tend to consume undamaged leaves and avoid previously damaged leaves ${ }^{47}$. Foliage damage in early spring, when trees have a higher specific leaf area and leaves are young, results in a greater reduction in leaf life span than if it occurred in species with a lower specific leaf area or with mature leaves ${ }^{48}$. Thus, we conclude that defoliators such as geometrids do not differ in their effects on leaf life span from other leaf miners or gall inducers. In species such as spruce, oak, and beech, levels of foliage deficit can increase even further in the years subsequent to droughts and heatwaves ${ }^{49,50}$. Indeed, thanks to climate change, droughts and heatwaves have increased noticeably in Europe over recent years, as has the occurrence of massive caterpillar infestations ${ }^{51}$, which has significantly increased the focus on developing adequate methods of prognosis ${ }^{52}$.

Our results showed that foliage loss corresponded with the number of all caterpillars at the sites. While the infested sites were shown to have significantly more O.brumata and E. defoliaria caterpillars than the CL site, the overall caterpillar assemblage at each infested site differed, with twice as many nontarget caterpillars found at HL. Populations of O.brumata and E. defoliaria are relatively easy to define spatially due to their weak dispersal ability, the females being flightless ${ }^{53}$, making dispersal between forest patches highly unlikely. We observed similarly high numbers of O.brumata and E. defoliaria at ZL and HL, but low numbers at CL. While both ZL and HL have stable populations of these pest geometrids, based on forester reports of repeated outbreaks, the CL population is either just starting to grow or is being suppressed by other predators (e.g. other arthropods or birds). While a higher caterpillar abundance and species diversity was likely to be the cause of the high level of foliage loss observed at HL (the highest of all sites studied), we were unable to definitively explain the high foliage loss, despite high bat flying activity, because we did not monitor the foraging activity of other predators, such as birds and arthropods, which could only have been done using exclosure experiments (see Bohm et al. ${ }^{54}$ ).

In conclusion, our results confirmed that pest caterpillars play an important role in the diet of both solely gleaning bat species, such as M. nattereri and M. bechsteinii, and that of species switching between foraging strategies, such as Plecotus spp. Furthermore, we were able to show that the aggregation and flying activity of such species increased significantly at infested sites during the spring emergence of caterpillars. Foliage damage was higher at infested sites compared with the control, with differences in the degree of damage directly related to the overall number of all caterpillar species present, rather than the abundance of our focus species, O. brumata and E. defoliaria. Nevertheless, one can assume that damage levels would have been higher still in the absence of bat predation. As both direct and indirect leaf damage is likely to increase in the face of climate change, we suggest that further experimental studies are needed as regards the relevance of bats in pest control, with special emphasis on their role in controlling pest caterpillar species.

\section{Methods}

Importance of model pest species. Oaks (Quercus spp.) are the most widespread and the most caterpillar-damaged deciduous tree species in Czech forestry ${ }^{55}$. In relation to biodiversity, oaks are considered a key species as they provide key habitat structures for cavity nesters and many other species ${ }^{55}$. Two of the most significant Central European oak pests are the geometrid moths Opheroptera brumata and Erannis defoliaria. While these do not completely destroy forests, they cause a significant loss of leaf area and have been the cause of several defoliation events over the past decades, thereby increasing the trees susceptibility to other types of damage, withering and reduced wood quality ${ }^{56}$. As drought conditions have increased over recent years with climate change, the negative impacts of tree pests on oaks have also increased ${ }^{52,57}$. Both geometrids have a similar annual life cycle, with caterpillars emerging in spring (April-May) and adult moths emerging in autumn (October-November $)^{58}$. Multi-year cycles occur every 7-11 years, when massive overpopulation and severe defoliation may occur ${ }^{52}$. Such outbreaks tend to be the result of (1) coincidental caterpillar emergence with sprouting of oaks due to higher early spring temperatures ${ }^{59}$ and, especially in more recent years, (2) increased time for mating during warmer winters.

Caterpillar availability. Three agricultural deciduous forests situated in southern Moravia, Czech Republic, were chosen for this study, two where spring outbreaks of geometrid caterpillars have repeatedly been observed in the past (Ždánický forest [ZL]; $350 \mathrm{~m}$ a. s. $1 . ; 49.02^{\circ} \mathrm{N}, 17.02^{\circ} \mathrm{E}$; the Holedná game reserve [HL]; $325 \mathrm{~m}$ a. s. $\left.1 . ; 49.21^{\circ} \mathrm{N}, 16.53^{\circ} \mathrm{E}\right)$ and one pest-free control site (CL; $350 \mathrm{~m}$ a. s. $\left.1 . ; 49.09^{\circ} \mathrm{N}, 17.02^{\circ} \mathrm{E}\right)$ (Fig. 1). At all three sites, the forest is predominantly made up of Quercus robur, Q. petraea, and Carpinus betulus, with less frequent occurrence of Fagus sylvatica.

The presence and size of caterpillars was checked on ten random trees at HL every week over April 2017. At the beginning of May, caterpillars were present on all control trees, suggesting that peak caterpillar abundance was imminent. Two separate sampling periods were established (group variable CATERPILLAR STATUS), the "before the peak" period lasting from 15 to 30 April, when caterpillars were present in low numbers and of small size $(<5 \mathrm{~mm})$ and probably not yet attractive prey, and "during peak" period from 1-16 May, when 
peak abundance occurred. In the "during the peak" period, we sampled all available sedentary prey (caterpillars and other arthropods) from five randomly selected trees (three branches of similar size on each tree) at each site using the beating method ${ }^{60}$. All caterpillars were determined according to the key of Macek et al..$^{58}$ and the website UKMOTHS ${ }^{61}$.

Foliage loss. Foliage loss was evaluated in mid-June after most of the caterpillars had pupated. Foliage damage was assessed on five randomly selected deciduous trees at each site, with ten leaves from three branches sampled from each tree (150 leaves per site). All leaves were scanned and the leaf coverage calculated (in $\mathrm{cm}^{2}$ ) using the software package ImageJ v1.5 (https://imagej.nih.gov/; NIH, USA). In the case of damaged leaves, we estimated the original coverage and the subsequent percentage loss in foliage coverage (in $\mathrm{cm}^{2}$ ). Samplings were carried out in accordance with Czech law No 289/1995.

Bat flying activity. At each site between mid-April and mid-May 2017, an SM4BAT detector (Wildlife Acoustics, Inc., Maynard, USA) equipped with an SMX-II microphone was set to record from sunset to sunrise. The detectors were attached to a tree trunk $6 \mathrm{~m}$ above the surrounding vegetation so that the branches did not block the microphones. The power supply and SD cards were replaced every 10 days. For the trigger system, the amplifier gain was set to $36 \mathrm{~dB}$ to ensure that only those events that were most likely to be bats were recorded. Recordings obtained in real-time were analysed with the Sonochiro v4 (http://sonochiro.biotope.fr/) software package (Biotope, Méze, France), using the northern temperate library of recordings (classifier). Software settings, post-processing and data analysis followed that of Bartonička et al. ${ }^{62}$. We focused on bat species that have the potential to forage on sedentary caterpillars, either solely gleaning predators (Myotis bechsteinii, Myotis nattereri) or both gleaning and aerial hawking predators (Plecotus auritus, Plecotus austriacus) ${ }^{21}$. For further analysis, we used the number of call sequences of two groups of foliage gleaners, i.e., the pair P. auritus/austriacus and M. bechsteinii/nattereri. Sequences were also grouped based on period (CATERPILLAR STATUS; before, during), and sampling site (SITE; ZL, HL, CL). Each echolocation sequence was determined on the species (or species pair) level with a minimum confidence index (MCI) ranging from 0 to $10\left(\mathrm{cf}^{62}\right)$. For each species, $15 \%$ of its sequences (range 3-485) were manually identified (Supplementary Table S1). The only exception was $P$. pipistrellus and $P$. pygmaeus, for which only $4 \%$ of the recordings were manually identified due to the high number of recordings. The MCI was determined at a value where $90 \%$ overlap was found in the determination of species identification using SonoChiro and manual identification ${ }^{62,63}$. To arbitrarily set the lowest value of the minimum confidence index, Batsound 4.12 (Pettersson Elektronik AB, Uppsala, Sweden) and Barataud ${ }^{64}$ were used. All $^{2}$ studied species, i.e., $P$. auritus, $P$. austriacus, $M$. nattereri, and M. bechsteinii, were repeatedly mist-netted at all three sites.

Dietary analysis. Bats were mist-netted at the overpopulation sites between April and May 2017 only. In total, we sampled $41 \mathrm{M}$. bechsteinii, seven M. nattereri, 32 P. auritus, and one P. austriacus. Each bat was placed separately in a linen bag and left for four hours to defecate, whereupon it was released at the same locality ${ }^{21}$ and the faeces stored separately in $96 \%$ ethanol. Linen bags were washed at high temperatures between uses. The bats were captured and handled under a license from the South Moravian Regional Authority, Permit no. JMK 63761/2017. Tomáš Bartonička is authorized to handle free-living bats under Certificate of Competency No. CZ01297 (\$17, Czech law No 246/1992). Each dropping sample then underwent morphological analysis, with each pellet placed on a petri dish with $96 \%$ ethanol, disrupted using a dissection needle and tweezers and inspected under a microscope (magnification ranging from $1.6 \times$ to $5.6 \times$ ) to confirm the remains of caterpillars. The percentage occurrence of identified taxa (\%oc) was estimated following McAney et al. ${ }^{65}$. For every twenty samples, we added one negative control sample (four in total) to test possible contamination. All instruments were sterilized by fire and the workstation including microscope was sterilized and bleached between the samples.

After morphological analysis, all 85 samples (including negative controls) underwent DNA isolation using the NucleoSpin DNA Stool kit (MACHEREY-NAGEL GmbH \& Co. KG, Düren, Germany), following the manufacturer's "Protocol for fresh or frozen stool samples" version April 2016/Rev. 01. There were four DNA isolation sessions $(3 \times 24$ samples and once 13 samples $)$ during each session, one negative control was included into the process.

Subsequent PCR amplification of the $157 \mathrm{bp}$ section of the COI mitochondrial gene was performed using the primers ZBJ-ArtF1c: 5'-GATATTGGAACWTTATATTTTATTTTTGG-3' and ZBJ-ArtR2c: 5'-WACTAATCA ATTWCCAAATCCTCC- $3^{\prime 66}$. These primers are frequently used in studies focusing on bat diet barcoding and are known to be biased towards Lepidopteran and Dipteran $\operatorname{taxa}^{67}$, and hence beneficial for our study. Unambiguous identification of subsequently pooled samples was ensured through unique combinations of MID-tagged primers. PCR thermal cycling conditions were as follows: $15 \mathrm{~min}$ at $95^{\circ} \mathrm{C}$, followed by 40 cycles of $30 \mathrm{~s}$ at $94{ }^{\circ} \mathrm{C}, 90 \mathrm{~s}$ at $50.5^{\circ} \mathrm{C}$ and $90 \mathrm{~s}$ at $72{ }^{\circ} \mathrm{C}$, followed by a final incubation of $10 \mathrm{~min}$ at $72^{\circ} \mathrm{C}$. The PCR products were visualised on a $1 \%$ agarose gel and purified using standard EXOCIP purification. Negative control samples showed no signs of amplification and thus were not sequenced. The purified PCR products were then pooled appropriately to achieve an equal DNA concentration (about $11 \mathrm{ng} / \mathrm{ul}$ ) and sent to a commercial sequencing facility. Sequencing was processed using the MiSeq Reagent Kit version 3 system (Illumina) by the SEQME company (Dobříš, Czech Republic; www.seqme.eu).

Bioinformatics analysis. We merged raw paired-end $250 \mathrm{bp}$ reads (ca. $3 \mathrm{M}$ reads) and made a quality check with the USEARCH v10 (https://www.drive5.com/) software package, using the algorithms -fastq_mergepairs, -fastq_trunctail 30 and -fastq_minovlen 50. This resulted in approximately $1.5 \mathrm{M}$ merged reads $(2.85 \%$ 
were filtered during the process). We then removed the tagged primers using the Python program Cutadapt v1.15 (https://cutadapt.readthedocs.io/), which also demultiplexed samples according to the tags ${ }^{68}$, thereby rejecting $51.1 \%$ of the merged reads. When using Cutadapt, we discarded all reads shorter than 150 bp and longer than $165 \mathrm{bp}$, thereby rejecting 1\% of demultiplexed reads. We then dereplicated reads using the USEARCH fastx_uniques algorithm, using the option minuniquesize 2 . The final read count was $>700,000$, with an average of 8737 reads per sample (MAX: 53,898; MIN: 1323). We then applied the USEARCH UNOISE3 algorithm to cluster these unique reads into zOTUs and automatically filter chimaeras. The reads were then mapped back to the original samples using the USEARCH otutab algorithm.

To match zOTUs with appropriate taxa at the highest level possible, we compared our data with the GENBANK database, using a minimum sequence similarity of $98 \%{ }^{69}$. When several prey species provided an equal best match, selection was based on the species known to be present in the study area. Moth species that feed on agricultural trees such as oak, hornbeam, spruce, or pine were determined as pest species.

Statistical analysis. To calculate the significance of sampling site and caterpillar status on bat flying activity, we used the following model for Plecotus (P. auritus/austriacus) and Myotis (M. bechsteinii/naterreri): $\log ($ sequences $)=\alpha+$ SITE + CATERPILLAR STATUS +SITE: CATERPILLAR STATUS. The Wald Chi-Squared test was then applied to reveal significant differences between sites for both bat groups. Analysis of flying activity was carried out using the lattice and geepack packages in R v. $4.0 .3^{70}$, using a poisson distribution model with $\log$ link. We used the geeglm model function with an AR1 correlation structure to counter autocorrelation in the time series data. Shapiro-Wilk normality tests were undertaken using the STATISTICA 12 statistics package (StatSoft, Inc, Tulsa, USA), as were Kruskal-Wallis H tests (caterpillar comparison among sites) and generalised linear model (GLM) for the analysis of foliage loss, based on percentage foliage loss per branch $\left(\% \mathrm{~cm}^{2}\right)$ with SITE (CL, HL, ZL) and total No. caterpillars as explanatory variables. The total number of caterpillars includes all caterpillars sampled on foliage and not just the focal species.

\section{Data availability}

The datasets generated and analysed during the current study are available from the corresponding author on reasonable request.

Received: 25 January 2021; Accepted: 11 June 2021

Published online: 01 July 2021

\section{References}

1. Solomon, M. E. The natural control of animal populations. J. Anim. Ecol. 18(1), 1-35 (1949).

2. Sinclair, A. R. E. \& Krebs, C. J. Complex numerical responses to top-down and bottom-up processes in vertebrate populations. Philos. Trans. R. Soc. B 357(1425), 1221-1231 (2002).

3. Readshaw, J. L. The numerical response of predators to prey density. J. Appl. Biol. 10, 342-351 (1973).

4. Boyles, J. G., Cryan, P. M., McCracken, G. F. \& Kunz, T. H. Economic importance of bats in agriculture. Science 332(6025), 41-42 (2011).

5. Taylor, P. J., Grass, I., Alberts, A. J., Joubert, E. \& Tscharntke, T. Economic value of bat predation services-a review and new estimates from macadamia orchards. Ecosyst. Serv. 30, 372-381 (2018).

6. Kunz, T. H., BraundeTorrez, E., Bauer, D., Lobova, T. \& Fleming, T. H. Ecosystem services provided by bats. Ann. N. Y. Acad. Sci. 1223, 1-38 (2011).

7. Russo, D., Bosso, L. \& Ancillotto, L. Novel perspectives on bat insectivory highlight the value of this ecosystem service in farmland: Research frontiers and management implications. Agric. Ecosyst. Environ. 266, 31-38 (2018).

8. Boyles, J. G., Sole, C. L., Cryan, P. M. \& McCracken, G. F. On estimating the economic value of insectivorous bats: prospects and priorities for biologists. In Bat Evolution, Ecology, and Conservation (eds Adams, R. A. \& Pedersen, S. C.) 501-515 (Springer, 2013).

9. Kemp, J. et al. Bats as potential suppressors of multiple agricultural pests: a case study from Madagascar. Agric. Ecosyst. Environ. 269, 88-96 (2019).

10. Kolkert, H., Andrew, R., Smith, R., Rader, R. \& Reid, N. Insectivorous bats selectively source moths and eat mostly pest insects on dryland and irrigated cotton farms. Ecol. Evol. 10(1), 371-388 (2019).

11. Weier, S. M. et al. Insect pest consumption by bats in macadamia orchards established by molecular diet analyses. Glob. Ecol. Conserv. 18, e00626 (2019).

12. Bohmann, K. et al. Molecular diet analysis of two African free-tailed bats (Molossidae) using high throughput sequencing. PLoS ONE 6(6), e21441 (2011).

13. Razgour, O. et al. High-throughput sequencing offers insight into mechanisms of resource partitioning in cryptic bat species. Ecol. Evol. 1(4), 556-570 (2011).

14. Cleveland, C. J. et al. Economic value of the pest control service provided by Brazilian free-tailed bats in south-central Texas. Front. Ecol. Environ. 4(5), 238-243 (2006).

15. McCracken, G. F. et al. Bats track and exploit changes in insect pest populations. PLoS ONE 7(8), e43839 (2012).

16. Maas, B. et al. Bird and bat predation services in tropical forests and agroforestry landscapes. Biol. Rev. 91(4), 1081-1101 (2015).

17. Maine, J. J. \& Boyles, J. G. Bats initiate vital agroecological interactions in corn. Proc. Natl. Acad. Sci. USA 112(40), 12438-12443 (2015).

18. Hill, D. S. Pests of Crops in Warmer Climates and Their Control (Springer, 2008).

19. Zhang, B. C. Index of Economically Important Lepidoptera (CAB International, Wallingford, 1994).

20. Riccucci, M. \& Lanza, B. Bats and insect pest control: a review. Vespertilio 17, 161-169 (2014).

21. Andreas, M., Reiter, A. \& Benda, P. Dietary composition, resource partitioning and trophic niche overlap in three forest foliagegleaning bats in Central Europe. Acta Chiropterol. 14(2), 335-345 (2012).

22. Vesterinen, E. J., Puisto, A. I. E., Blomberg, A. S. \& Lilley, T. M. Table for five, please: dietary partitioning in boreal bats. Ecol. Evol. 8, 10914-10937 (2018).

23. Hope, R. P. et al. Second generation sequencing and morphological faecal analysis reveal unexpected foraging behaviour by $M y o t i s$ nattereri (Chiroptera, Vespertilionidae) in winter. Front. Zool. 11, 39 (2014).

24. Costa, A. et al. Structural simplification compromises the potential of common insectivorous bats to provide biocontrol services against the major olive pest Pray oleae. Agric. Ecosyst. Environ. 287, 106708 (2020). 
25. Garin, I. et al. Bats from different foraging guilds prey upon the pine processionary moth. PeerJ 7, e7169 (2019).

26. Puig-Montserrat, X. et al. Pest control service provided by bats in Mediterranean rice paddies: linking agroecosystems structure to ecological functions. Mamm. Biol. 80, 237-245 (2015).

27. Elgar, M. A. Predator vigilance and group size in mammals and birds: a critical review of the evidence. Biol. Rev. 64, 13-33 (1989).

28. Fukui, D., Murakami, M., Nakano, S. \& Aoi, T. Effect of emergent aquatic insects on bat foraging in a riparian forest. J. Anim. Ecol. 75(6), 1252-1258 (2006).

29. Partridge, D. R., Parkins, K. L., Elbin, S. B. \& Clark, J. A. Bat activity correlates with moth abundance on an urban green roof. Northeast Nat. 27(1), 77-89 (2020).

30. Charbonnier, Y., Barbaro, L., Theillout, A. \& Jactel, H. Numerical and functional responses of forest bats to a major insect pest in pine plantations. PLoS ONE 9(10), e109488 (2014).

31. Krauel, J. J., Ratcliffe, J. M., Westbrook, J. K. \& McCracken, G. F. Brazilian free-tailed bats (Tadarida brasiliensis) adjust foraging behaviour in response to migratory moths. Can. J. Zool. 96(6), 513-520 (2018).

32. Gregor, F. \& Bauerová, Z. The role of Diptera in the diet of Natterer's bat, Myotis nattereri. Folia. Zool. 36(1), 13-19 (1987).

33. Swift, S. \& Racey, P. Gleaning as a foraging strategy in Natterer's bat Myotis nattereri. Behav. Ecol. Sociobiol. 52(5), 408-416 (2002).

34. Taake, K. H. Resource utilization strategies of vespertilionid bats hunting over water in forests. Myotis 30, 7-74 (1992).

35. Vaughan, N. The diets of British bats (Chiroptera). Mammal. Rev. 27(2), 77-94 (1997).

36. Siemers, B. \& Swift, S. M. Differences in sensory ecology contribute to resource partitioning in the bats Myotis bechsteinii and Myotis nattereri (Chiroptera: Vespertilionidae). Behav. Ecol. Sociobiol. 59, 373-380 (2006).

37. Norberg, U. M. \& Rayner, J. M. V. Ecological morphology and flight in bats (Mammalia; Chiroptera): wing adaptations, flight Performance, foraging strategy and echolocation. Philos. Trans. R. Soc. B 316(1179), 335-427 (1987).

38. Entwistle, A. C., Racey, P. A. \& Speakman, J. R. Habitat exploitation by a gleaning bat, Plecotus auritus. Philos. Trans. R. Soc. B 351(1342), 921-931 (1996).

39. Kerth, G., Wagner, M. \& König, B. Roosting together, foraging apart: information transfer about food is unlikely to explain sociality in female Bechstein's bats (Myotis bechsteinii). Behav. Ecol. Sociobiol. 50, 283-291 (2001).

40. Rydell, J. Food habits of northern (Eptesicus nilssoni) and brown long-eared (Plecotus auritus) bats in Sweden. Holarct. Ecol. 12(1), 16-20 (1989).

41. Anderson, M. E. \& Racey, P. A. Feeding behaviour of captive brown long-eared bats, Plecotus auritus. Anim. Behav. 42(3), 489-493 (1991).

42. Andreas, M. Feeding ecology of a bat community. Ph.D. Thesis, Czech Agriculture University, Prague (2002).

43. Dobbertin, M. Tree growth as indicator of tree vitality and of tree reaction to environmental stress: a review. Eur. J. Forest. Res. 124, 319-333 (2005).

44. Keena, M. A., Côté, M. J., Grinberg, P. S. \& Wallner, W. E. World distribution of female flight and genetic variation in Lymantria dispar (Lepidoptera: Lymantriidae). Environ. Entomol. 37(3), 636-649 (2008).

45. Melin, M., Viiri, H., Tikkanen, O. P., Elfving, R. \& Neuvonen, S. From a rare inhabitant into a potential pest-status of the nun moth in Finland based on pheromone trapping. Silva. Fenn. 54(1), 1-9 (2020).

46. Kuhlman, H. M. Effects of insect defoliation on growth and mortality of trees. Annu. Rev. Entomol. 16, 289-324 (1971).

47. Bogacheva, I. A. Repeated damage of leaves by phyllophagous insects: is it influenced by rapid inducible resistance? In Forest Insect Guilds: Patterns of Interaction with Host Trees. (eds. Baranchikov, Y.N., Mattson, W.J., Hain, F.P. \& Payne, T.L.) 113-122 (U.S. Dep. Agric. For. Serv. Gen. Tech. Rep. NE-153, 1991).

48. Zvereva, E. L. \& Kozlov, M. V. Effects of herbivory on leaf life span in woody plants: a meta-analysis. J. Ecol. 102(4), 873-881 (2014).

49. Bréda, N., Huc, R., Granier, A. \& Dreyer, E. Temperate forest trees and stands under severe drought: a review of ecophysiological responses, adaptation processes and long-term consequences. Ann. For. Sci. 63, 625-644 (2006).

50. Clark, J. S. et al. The impacts of increasing drought on forest dynamics, structure, and biodiversity in the United States. Glob. Change Biol. 22, 2329-2352 (2016).

51. Delb, H. Eichenschädlinge im Klimawandel in Südwestdeutschland. FVA-einblick. 2/2012, 11-14 (2012).

52. Hittenbeck, A., Bialozyt, R. \& Schmidt, M. Modelling the population fluctuation of winter moth and mottled umber moth in central and northern Germany. For. Ecosyst. 6, 4 (2019).

53. Ims, R. A., Yoccoz, N. G. \& Hagen, S. B. Do sub-Arctic winter moth populations in coastal birch forest exhibit spatially synchronous dynamics?. J. Anim. Ecol. 73, 1129-1136 (2004).

54. Böhm, S. M., Wells, K. \& Kalko, E. K. V. Top-down control of herbivory by birds and bats in the canopy of temperate broad-leaved oaks (Quercus robur). PLoS ONE 6(4), e17857 (2011).

55. Patočka, J. Caterpillars on oaks in Czechoslovakia. (Štátne pôdohospodárske nakladatelstvo: 262, 1954).

56. Hausmann, A. The geometrid moths of Europe, Volume 1: Introduction, Archiearinae, Orthostixinae, Desmobathrinae, Alsophilinae, Geometrinae, (Apollo Books, 2001).

57. Zahradník, P. Calamities in Czech forests_-past and present. In: Facts and myths about Czech agricultural forestry. Proceedings of papers (ed Stonawski, J.) 31-51 (Česká zemědělská univerzita, 2008).

58. Macek, J., Procházka, J. \& Traxler, L. Butterflies and caterpillars of Central Europe: Moths III. - Geometrids. (Academia, 2012).

59. Liška, J. Winter moth, Operophtera brumata L. Lesnická Práce, 11: I-IV (2002).

60. Basset, Y., Springate, N. D., Aberlenc, H. P. \& Delvare, G. A review of methods for sampling arthropods in tree canopies. In Canopy Arthropods (eds Stork, N. E. et al.) 567 (Chapman \& Hall, 1997).

61. Kimber, I. UKMOTHS. https://ukmoths.org.uk (2015).

62. Bartonička, T., Miketová, N. \& Hulva, P. High throughput bioacoustic monitoring and phenology of the greater noctule bat (Nyctalus lasiopterus) compared to other migratory species. Acta Chiropterol. 21(1), 75-85 (2019).

63. Lemen, C., Freeman, P. W., White, J. A. \& Andersen, B. R. The problem of low agreement among automated identification programs for acoustical surveys of bats. West. N. Am. Naturalist. 75(2), 218-225 (2015).

64. Barataud, M. Acoustic Ecology of European Bats. Species Identification and Studies of Their Habitats and Foraging Behaviour (Biotope \& National Museum of Natural History, 2015).

65. McAney, C., Shiel, C., Sullivan, C. \& Fairley, J. The analysis of bat droppings (An occasional publication of the Mammal society; no. 14, 1991).

66. Zeale, M. R., Butlin, R. K., Barker, G. L., Lees, D. C. \& Jones, G. Taxon-specific PCR for DNA barcoding arthropod prey in bat faeces. Mol. Ecol. Resour. 11(2), 23-44 (2011).

67. Clarke, L. J., Soubrier, J., Weyrich, L. S. \& Cooper, A. Environmental metabarcodes for insects: in silico PCR reveals potential for taxonomic bias. Mol. Ecol. Resour. 14, 1160-1170 (2014).

68. Martin, M. Cutadapt removes adapter sequences from high-throughput sequencing reads. EMBnetjournal 17, 10-12 (2011).

69. Benson, D. A., Karsch-Mizrachi, I., Lipman, D. J., Ostell, J. \& Wheeler, D. L. GenBank. Nucleic Acids Res. 35, 21-25 (2007).

70. R Core Team. R: language and environment for statistical computing. Vienna, Austria: R Foundation for Statistical Computing. https://www.r-project.org/ (2019). 


\section{Acknowledgements}

We would like to express especial thanks to Kevin Roche for substantially editing the English language and improving the manuscript overall. We also thank the South Moravian Regional Authority (Permit JMK 63761/2017) for providing permits for mist netting. This project was supported by Masaryk University, Brno, Czech Republic (\# MUNI/A/1078/2017, MUNI/A/1436/2018).

\section{Author contributions}

J.B. and T.B. conceived and designed the research. J.B. with T.B. sampled the bat droppings. J.B. performed all other sampling together with morphological analysis of the droppings. J.B. and A.K. performed the molecular analysis and bioinformatics. J.B. is the author of photos and he wrote the first draft. All authors contributed during the writing of the manuscript and approved the final version.

\section{Competing interests}

The authors declare no competing interests.

\section{Additional information}

Supplementary Information The online version contains supplementary material available at https:/doi.org/ 10.1038/s41598-021-93104-z.

Correspondence and requests for materials should be addressed to J.B.

Reprints and permissions information is available at www.nature.com/reprints.

Publisher's note Springer Nature remains neutral with regard to jurisdictional claims in published maps and institutional affiliations.

(c) (i) Open Access This article is licensed under a Creative Commons Attribution 4.0 International License, which permits use, sharing, adaptation, distribution and reproduction in any medium or format, as long as you give appropriate credit to the original author(s) and the source, provide a link to the Creative Commons licence, and indicate if changes were made. The images or other third party material in this article are included in the article's Creative Commons licence, unless indicated otherwise in a credit line to the material. If material is not included in the article's Creative Commons licence and your intended use is not permitted by statutory regulation or exceeds the permitted use, you will need to obtain permission directly from the copyright holder. To view a copy of this licence, visit http://creativecommons.org/licenses/by/4.0/.

(C) The Author(s) 2021 